\title{
MICROORGANISMOS ASOCIADOS A FRUTOS EMBOLSADOS DE GUAYABA TAIWANESA VARIEDAD TAI KUO ${ }^{1}$
}

\author{
Rossy Morera-Montoya ${ }^{2}$,Helga Blanco-Metzler ${ }^{3}$
}

\section{RESUMEN}

Microorganismos asociados a frutos embolsados de guayaba taiwanesa variedad Tai Kuo. El presente trabajo se efectuó con el objetivo de identificar microorganismos asociados al fruto de la guayaba en frutos embolsados de una plantación comercial en Carrillo de Poás, Alajuela, Costa Rica, durante la época seca y lluviosa del año 2007. Se realizaron aislamientos en el laboratorio para determinar la presencia y tipo de microorganismo asociado a los síntomas. Se utilizaron cuatro tipos diferentes de material para embolsar: papel encerado, tergal (bolsa de nylon), papel de directorio telefónico y la bolsa taiwanesa. El tejido dañado fue cultivado en medio PDA and PDA + ácido láctico, y los aislamientos se transfirieron a YDC, agar King y trozos de papa para identificar posibles bacterias. En ambas épocas los microorganismos identificados fueron: Colletotrichum sp., Pseudomonas, Pestalotia y dos no identificados. Durante la época seca se encontraron diferencias altamente significativas $(\mathrm{X} 2=$ 7,52 x 10 -4) para la incidencia de patógenos en el siguiente orden: control $>$ bolsa de papel de directorio telefónico $>$ bolsa de tergal $>$ bolsa Taiwanesa $>$ bolsa de papel encerado. Durante la época lluviosa también se encontraron diferencias altamente significativas $(X 2=0,04773)$ en la incidencia de microorganismos, teniendo como resultado: cuando control $>$ bolsa de tergal $>$ bolsa Taiwanesa. Los resultados sugieren que los microorganismos aislados de frutos enfermos podrían ser agentes responsables de la pérdida de frutas comerciales en las plantaciones tropicales de guayaba.

Palabras clave: Pudrición apical, antracnosis, Pestalotia, Pseudomonas, Cylindrocladium.

\begin{abstract}
Microorganisms associated to taiwanese guava fruits var. Tai Kuo. This study was conducted to identify a putative guava microorganisms observed on bagged fruits in a commercial plantation established in Carrillo de Poás, Alajuela, Costa Rica, during the dry and rainy seasons of year 2007. Laboratory isolations were conducted to determine the presence and nature of the microorganisms associated to the symptoms. Four different materials were used to bag the fruits: wax paper, tergal (nylon bag), telephone directory paper and Taiwanese bag. Damaged tissues were placed in PDA and PDA + lactic acid as culture media, and the isolates were transferred to YDC, King agar and potato fleshy tissue to identify possible bacteria. Microorganisms identified in both seasons were: Colletotrichum sp., Pseudomonas, Pestalotia and two unidentified microorganisms. Highly significant differences were found $(X 2=7,52 \times 10-4)$ in the incidence of the diseases in the following ranking: control $>$ telephone directory paper bags $>$ tergal bags $>$ Taiwanese bag $>$ wax paper bags, during the dry season. Highly significant differences were also found $(X 2=0,04773)$ for microorganisms incidence during the rainy season, when control $>$ tergal bag $>$ Taiwanese bag. The results suggest that the microorganism isolated from diseased fruits could be responsible for losses of commercial fruits in tropical guava field plantations.
\end{abstract}

Keywords: Apical rot, anthracnosis, Pestalotia, Pseudomonas, Cylindrocladium.

\footnotetext{
Recibido: 8 de octubre, 2008. Aceptado: 16 de noviembre, 2009. Parte de la tesis de licenciatura del primer autor.

2 Estación Experimental Fabio Baudrit Moreno, Universidad de Costa Rica. Alajuela, Costa Rica. rossymorera@yahoo.com

3 Centro de Investigaciones en Protección de Cultivos (CIPROC). Universidad de Costa Rica. San José, Costa Rica. helgablanco@yahoo.com
} 


\section{INTRODUCCIÓN}

La producción de guayaba taiwanesa en Costa Rica ha crecido los últimos años; esta fruta fue introducida en el mercado nacional por su delicioso sabor y ahora forma parte importante de los cultivos no tradicionales que se comercializan a nivel nacional (SEPSA 1998, Román y Juang 1999).

La guayaba es atacada por la mosca de la fruta (Anastrepha striata y Ceratitis capitata) durante todo el año (Coto y Saunders 2004). Los mecanismos de supervivencia de estas moscas son muy eficientes, y su daño genera altas pérdidas, por lo que el control químico ha sido en vano. Por tal razón, se han propuesto diversas prácticas de manejo integrado, de las cuales la más utilizada es la exclusión de la mosca por medio de una cobertura a la fruta con bolsas. Esta práctica ha presentado una alta eficacia de combate y reduce la cantidad de residuos químicos en el fruto (Mendes 1995).

El embolsado ha tenido mucho éxito en el combate de la plaga; sin embargo cada material crea un microclima diferente, el cual influye directamente en la calidad del fruto y la incidencia de microorganismos. Materiales como el plástico, podrían generar un microclima alto en humedad y temperatura, principalmente en la parte superior de la copa del árbol, generando un ambiente propicio para el desarrollo de los hongos Colletotrichum sp., Macrophomina sp., Phomopsis sp., Pestalotia sp., o daños causados por cochinillas, escamas o ácaros (Mendes 1995).

Según Román y Juang (1999), la enfermedad más común en los frutos de guayaba es antracnosis, la que se puede combatir con mancozeb, captan, clorotalonil, entre otros. Para Mendes (1995), aparte de la antracnosis, también se presenta un tipo de lesión que seca el tejido causado por la bacteria Erwinia psidii. Además, en un estudio realizado en Venezuela, donde se pretendía analizar la micoflora asociada a la guayaba (Pérez et al. 2000), encontraron esporas de varios géneros como: Dothiorella, Cladosporium, Alternaria, Helminthosporium, Curvularia, Fusarium, y Pestalotia. Este trabajo no especificó cuáles de estos hongos son capaces de atacar el fruto.

Debido a la diversa cantidad de microorganismos que se han informado en diferentes áreas productoras del mundo, en condiciones climáticas y de manejo diferentes, el objetivo de este trabajo fue determinar la población de microorganismos presentes en frutos de guayaba embolsados, en condiciones comerciales de manejo en Costa Rica.

\section{MATERIALES Y MÉTODOS}

La investigación se realizó en una plantación comercial de guayaba Taiwanesa variedad Tai-Kuo, perteneciente a la empresa Guayatica SA, ubicada dentro de las coordenadas $\mathrm{N} 10,02444^{\circ}$ y W 84,27425 , a los 814 msnm, en Carrillos de Poás, provincia de Alajuela, Costa Rica. Según las zonas de vida de Holdridge, esta zona se cataloga tipo bosque húmedo premontano (Tosi 1969), su precipitación promedio anual es de 2.192 $\mathrm{mm}$, su temperatura promedio es de $26^{\circ} \mathrm{C}$, la velocidad media del viento es $11,9 \mathrm{~km} / \mathrm{h}$ y la humedad relativa promedio es de $79 \%$ (Instituto Meteorológico de Costa Rica 2006). Los suelos son Andisoles y el terreno presenta un $20 \%$ de pendiente. Esta zona corresponde a una zona de alta incidencia para la plaga de la mosca de la fruta según el Programa Nacional de Moscas de la Fruta (Saborío 2006 ${ }^{4}$ ), entre ellos A. striata.

El ensayo se realizó en un lote con árboles de dos años de edad, reproducidos por semilla. La parcela posee distancias de siembra variables, pero en promedio las distancias entre filas eran de 3,5 $\mathrm{m}$ y entre árboles de 1,5 metros para una densidad de siembra de 1.904 árboles/ ha.

La práctica de embolsado se realiza con el fin de colocar una barrera física que proteja los frutos pequeños del ataque de la mosca de la fruta. La bolsa se debe asir de la rama más próxima mediante algún cierre especial de alambre flexible recubierto con algún plástico para evitar el herrumbre, su caída y el estrangulamiento del pecíolo. A este tipo de barrera física se le deja una abertura en la parte de abajo para el paso del aire y el óptimo drenaje del agua de lluvia.

El diseño experimental fue de seis tratamientos: bolsa de nylon, Taiwán, bolsa de papel encerado, papel directorio telefónico y control (o sin bolsa), distribuidos en seis bloques completos al azar con seis repeticiones.

Se evaluaron dos épocas de embolsado, la primera inició el 21 de febrero del 2007 y terminó con la última

\footnotetext{
4 Saborío, A. 2006. Zonas de incidencia en mosca de la fruta en Costa Rica. Especialista en mosca de la fruta. Ministerio de Agricultura y Ganadería (MAG). Comunicación personal. San José, Costa Rica.
} 
semana de cosecha el 14 de agosto del 2007 (175 días: época seca y transición a la lluviosa); la segunda época de embolsado tuvo lugar del 27 de junio hasta el 20 de noviembre del 2007 (146 días: condición lluviosa).

Los materiales de embolsados utilizados fueron:

a) Nylon cristal: se confeccionaron bolsas de tela de nylon cristal de color blanco, de $17 \mathrm{~cm}$ de ancho x $28 \mathrm{~cm}$ de largo. Se trató de simular la bolsa Taiwán pequeña, la cual tiene una pequeña abertura en la parte posterior de aproximadamente $5 \mathrm{~cm}$, para que el agua escurra y la bolsa no ejerza mucho peso sobre el fruto y éste pueda caer.

b) Tipo Taiwán: se utilizó la bolsa comercial tipo "Taiwán" de $17 \mathrm{~cm}$ de ancho x $28 \mathrm{~cm}$ de largo, la cual está fabricada a partir de fibra de madera de pino, que le confiere cierta repelencia a la mosca de la fruta $\left(\right.$ Chen $\left.2006^{5}\right)$, también está parafinada y posee un gramaje superior a $48 \mathrm{~g} / \mathrm{m}^{2}$ aproximadamente. Además, en la parte inferior cuenta con una abertura de $5 \mathrm{~cm}$ de diámetro, y en la parte superior trae un alambre para cerrar la bolsa.

c) Papel encerado: se confeccionaron bolsas a partir de papel encerado de $21 \mathrm{~cm}$ x $30 \mathrm{~cm}$, con el fin de seguir el modelo de la bolsa Taiwán. Se realizó el mismo tipo de abertura en la parte posterior de la bolsa. Como este material no se puede adherir con goma blanca, se decidió utilizar grapas para cerrar los lados.

d) Hojas de directorio telefónico: se confeccionaron bolsas a partir de hojas blancas de directorio telefónico de $21 \mathrm{~cm}$ x $28 \mathrm{~cm}$. El papel utilizado para esto es el papel periódico estándar, de gramaje de 48,8 $\mathrm{g} / \mathrm{m}^{2}$. Se pegaron a los lados con goma blanca y se dejaron abiertas en los extremos. Los productores de la Meseta Central utilizan esta bolsa en la producción comercial de guayaba.

\section{Manejo de la parcela experimental (poda y fertili- zación)}

Se podaron los árboles de la parcela para inducir la floración de forma similar, de manera que se pudiera disponer de frutos cuya madurez fuera fisiológicamente similar. Se eliminaron los brotes y ramas ortotrópicas, enfermas, débiles, además de algunos ápices.

\footnotetext{
5 Chen, T. 2006. Bolsas Taiwán. Biociencia. Comunicación personal. Cartago, Costa Rica.
}

Dentro del programa de fertilización de la finca, se aplicaron $30 \mathrm{~g}$ de 10-20-20/ árbol y $30 \mathrm{~g}$ de Magnesamón/árbol, durante la etapa de brotación, renovación y formación de yemas (inicios de época seca y de la lluviosa). Cuando la fruta se encontraba en desarrollo, se aplicó cada mes 30 g/árbol de 15-331 y 30 g/árbol de Magnesamón. En el mes de mayo y a finales de la época lluviosa se aplicaron $300 \mathrm{~g}$ de Cal-Mag/árbol.

Se aplicó 50 g/planta de 18-5-15-6-2 distribuidos en dos hoyos (5-10 $\mathrm{cm}$ de profundidad) a $30-40 \mathrm{~cm}$ de la base del árbol (25 g/hoyo); las fertilizaciones se realizaron cada 22 días.

Previo al inicio del ensayo se aplicó glifosato (1 1/ha) y metsulfurón metil (6 g i.a/ha) para el control de arvenses dentro de la finca.

Una vez embolsados los frutos, se realizaron aplicaciones de productos químicos para el respectivo manejo de microorganismos en las hojas y plagas insectiles (Cuadro 1); cada plan se aplicó cada 22 días. Además, el productor realizó aplicaciones cada 15 días de foliares como complemento de la nutrición de la plantación.

A los 26 días después del embolsado (dde), se eliminaron todos los frutos de los árboles que no estaban siendo evaluados, para evitar el crecimiento poblacional de la mosca de la fruta, capaz de perjudicar a los frutos de la segunda época de embolsado. Además, con la aparición de las primeras lluvias, se podría aumentar la población de microorganismos.

A los 72 dde se realizó la técnica del agobio en algunas ramas de los árboles para evitar la poda, ya que a través de ésta se induce el crecimiento vegetativo, lo cual podría provocar un estancamiento en el llenado del fruto.

Durante la segunda etapa de la investigación, se aplicó etoprofós granulado (10 g/árbol) para el control de jobotos.

Durante la época seca se observaron algunas deficiencias nutricionales de magnesio, potasio y fósforo en las hojas, por lo que se decidió fertilizar con $100 \mathrm{~g}$ de la fórmula comercial 18-5-15-6-2/planta, fórmula química. Estas fertilizaciones se realizaron cada 22 días.

Un mes después de establecido el segundo ensayo (época lluviosa), se podaron todos los árboles y se raleó la fruta expuesta. Para el control de arvenses se pasó motoguadaña cada 15 días. 


\section{Primer época de evaluación (transición época seca- época lluviosa)}

Se embolsaron 35 frutos de 15 a 22 mm de diámetro (medidos con un calibrador Fowler Euro-Cal Mark III de Sylvac), aparentemente sanos, libres de manchas y defectos en la cáscara.

Se colocaron todos los tratamientos por árbol individual (cinco árboles por bloque), al azar y en toda la periferia; se embolsaron siete frutos por tratamiento previniendo la abscisión por manipulación de frutos jóvenes, pero se evaluaron únicamente seis.

Se eliminaron los frutos que crecieron cerca del embolsado (raleo) para que no interfirieran con su crecimiento, o que ejercieran peso y provocaran su caída al suelo. También se eliminaron los frutos enfermos o dañados que sirvieran de foco de dispersión de inóculo dentro de la parcela experimental.

Las bolsas de papel encerado y de directorio telefónico se cerraron con grapas, y se sostuvieron de la rama central para que el peso sobre el pedúnculo no fuera excesivo. Para la bolsa de nylon se utilizó una cinta de alambre que cerraba la bolsa y la sostenía de la rama central; la bolsa Taiwán utilizó su propio cierre metálico. Cada fruto se etiquetó para evaluar su diámetro, altura inicial y final.

El fruto se cosechó por los productores de guayaba, cuando cambiaba de color a un verde pálido y se hacía más chato; es decir cuando aumenta el diámetro ecuatorial y disminuía su crecimiento en diámetro meridional, momento óptimo para que sea cosechado, según Mora y Loría (2006 $)$.

La incidencia de microorganismos asociados al fruto se evaluó por la presencia de síntomas. De esas lesiones se realizaron aislamientos que posteriormente se detallan.

\section{Segunda época de evaluación (época lluviosa)}

Antes de establecer el segundo periodo del ensayo, se podó para estimular la planta a brotar, que diera floración y mayor producción; además, de evitar la obstrucción del paso de la luz, mejorar la ventilación y disminuir la aparición de enfermedades y algas.

Para la segunda época de embolsado se evaluaron

6 Mora, E; Loría, CL. 2006. Índice de cosecha para guayaba taiwanesa. Estación Experimental Fabio Baudrit Moreno. Comunicación personal. sólo los tratamientos con bolsa nylon y bolsa Taiwán, además del tratamiento testigo ya que, el primer ensayo se encontró que los materiales de papel encerado y hojas de directorio presentaron poca durabilidad en el campo (antes de los 20 dde). Para esta época se utilizaron 21 árboles. La caída de frutos durante la primera época mostraron un diámetro ecuatorial entre los 15 y $17 \mathrm{~mm}$. Se embolsaron los frutos con un diámetro entre 17 y $20 \mathrm{~mm}$. Además, en la bolsa nylon se utilizó un alambre más delgado, protegido por un plástico para evitar su oxidación y la contaminación del fruto), asegurar un buen cierre de la bolsa y evitar la entrada de insectos.

\section{Identificación de fitomicroorganismos}

Para identificar microorganismos asociados a los frutos de guayaba se tomaron diferentes muestras con distintos síntomas que aparecieron en el campo, se lavó bien la fruta, se realizó una descripción detallada del síntoma y se dispuso el material en medio Papa Dextrosa Agar (PDA) solo y PDA con ácido láctico de la siguiente manera: se seleccionaron segmentos de material con inicio de lesión (los segmentos contenían mitad sano y mitad enfermo), se guardaron en un plato petri y se identificaron. Cuando el PDA estuvo listo y gelificado se tomó tejido proveniente de material interno del fruto, con la ayuda de unas pinzas y de un bisturí, y se colocaron cinco segmentos de material, se tapó el plato petri, se identificó, y guardó en la cámara de incubación a temperatura ambiente.

Para las lesiones externas, se colocaron los segmentos de epidermis en pequeñas estructuras plásticas con orificios, se sumergieron en alcohol de $70^{\circ}$ por un minuto, luego se sumergieron en hipoclorito de sodio $(0,5 \%)$ por 30 segundos, y se hicieron dos lavados con agua destilada. Luego se segmentó el material y se colocó cinco fragmentos en el plato con el medio de crecimiento.

Se purificaron los hongos que crecieron en conjunto (se extrajo un trozo de la zona de avance del hongo y se colocó en PDA). Se pasaron a platos con PDA y se introdujeron en la cámara de incubación a temperatura ambiente.

Una vez crecido el micelio de los hongos, se tomó del centro de la colonia, y se observaron al microscopio las estructuras para su respectiva identificación. Las bacterias encontradas se transfirieron a medio nutritivo (NA). Una vez crecidas las colonias, se colocaron en 
Cuadro 1. Programa de manejo agronómico de la parcela donde se evaluó la población de microorganismos en frutos de guayaba embolsados. Carrillos, Alajuela, Costa Rica. 2007.

\begin{tabular}{|c|c|c|c|c|c|}
\hline Producto & Plan 1 & Plan 2 & Plan 3 & Plan 4 & Plan 5 \\
\hline Surfactante & Dodecil bencen + non & I fenol etoxilado sulfon & ato de sodio $(250 \mathrm{ml} /$ & $001)$ & \\
\hline Insecticidas & $\begin{array}{l}\text { Clorpirifós }(300 \mathrm{ml} / \\
\text { estañón) }\end{array}$ & $\begin{array}{l}\text { Cipermetrina } \\
\text { ml/ estañón })\end{array}$ & $\begin{array}{l}\text { Dicofol }(0,5 \text { 1/ esta- } \\
\text { ñón) }\end{array}$ & $\begin{array}{l}\text { Lambda-cihalotrina } \\
\text { ( } 250 \text { ml/estañón) }\end{array}$ & $\begin{array}{l}\text { Diazinon } \\
\text { (300 ml/estañón) }\end{array}$ \\
\hline $\begin{array}{l}\text { Insecticidas } \\
\text { naturales }\end{array}$ & & $\begin{array}{l}\text { Aceite de semillas de } \\
\text { Neem }(300 \mathrm{ml} / \text { es- } \\
\text { tañón) }\end{array}$ & & $\begin{array}{l}\text { Aceite Vegetal } \\
\text { (250 ml/estañón) }\end{array}$ & $\begin{array}{l}\text { Aceite de semillas de } \\
\text { Neem } \\
\text { (300 ml/estañón) }\end{array}$ \\
\hline Fungicidas & $\begin{array}{l}\text { Captan } \\
\text { (300 g/estañón) }\end{array}$ & $\begin{array}{l}\text { Benomil } \\
\text { (250 g/estañón) }\end{array}$ & $\begin{array}{l}\text { Metil tiofanato } \\
\text { (250 g/estañón) }\end{array}$ & $\begin{array}{l}\text { Iprodione } \\
\text { (250 ml/estañón) }\end{array}$ & $\begin{array}{l}\text { Antracol } 750 \\
\text { g/estañón }\end{array}$ \\
\hline \multirow{3}{*}{ Foliares } & $\begin{array}{l}\text { Nitrato de magnesio } \\
(1 \mathrm{~kg} \text { /estañón })\end{array}$ & $\begin{array}{l}\text { Fosfato monopotási- } \\
\text { co }(1 \mathrm{~kg} / \text { estañón })\end{array}$ & $\begin{array}{l}\text { Sulfato de magnesio } \\
(1 \mathrm{~kg} / \text { estañón })\end{array}$ & $\begin{array}{l}\text { Sweed } \\
\text { (250 ml/estañón) }\end{array}$ & $\begin{array}{l}\text { Azufre } \\
(0,5 \mathrm{~kg} / \text { estañón })\end{array}$ \\
\hline & $\begin{array}{l}\text { Calcio y boro } \\
(0,51 \text { /estañón })\end{array}$ & $\begin{array}{l}\text { Polisacáridos } \\
\text { (1 kg/estañón) }\end{array}$ & Zinc (0,5 1/estañón) & $\begin{array}{l}\text { Wural Potasio } \\
(0,5 \text { 1/estañón })\end{array}$ & $\begin{array}{l}\text { Calcio y boro } \\
(0,5 \text { 1/estañón })\end{array}$ \\
\hline & & & $\begin{array}{l}\text { Wural Potasio } \\
(0,5 \text { 1/estañón })\end{array}$ & & $\begin{array}{l}\text { Polisacáridos } \\
\text { (1 kg/estañón) }\end{array}$ \\
\hline
\end{tabular}

medio YDC, Agar King y en papa para identificar el género. El medio Agar King se utilizó para identificar la presencia de bacterias del género Pseudomonas; estas colonias en presencia de la luz ultravioleta obtienen una coloración amarilla fluorescente.

El medio YDC sirvió para identificar si aparecían bacterias del género Xanthomonas, las cuales adquieren una coloración amarillo fuerte o amarillo marrón al colocarlas contra luz ultravioleta.

Para corroborar si alguna de las bacterias encontradas corresponde a la pudrición suave del género Erwinia, se realizaron aislamientos en papa. Se tomaron pedacitos de papel toalla y papel aluminio, se autoclavaron a $120-121^{\circ} \mathrm{C}$ por 15 minutos, luego se colocaron en platos petri estériles. Primero se colocó el papel toalla, previamente humedecido con agua destilada estéril para dejar disponible el agua libre a las bacterias, luego el papel aluminio para que sirviera de obstáculo con el contacto directo al papel. Por aparte, se tomaron las papas, se lavaron y se sumergieron en alcohol de $95^{\circ}$, se cortaron trocitos y se rociaron con alcohol de $95^{\circ}$, y se enjuagaron con agua destilada estéril. Cada trozo se colocó con ayuda de pinzas a los diferentes platos y se les realizó un rayado con la bacteria.

\section{Análisis de datos}

Los datos se examinaron por medio de un análisis de varianza y LSD Fisher para detectar diferencias significativas entre tratamientos para las variables de fruto protegido; también, se realizó una separación de medias a través de la prueba de Tukey al 0,05.

Igualmente, se realizaron pruebas de Chi cuadrado; este tipo de análisis determina si existen o no patrones de distribución en las enfermedades o en el ataque de plagas insectiles.

\section{RESULTADOS Y DISCUSIÓN}

\section{Clima durante el ensayo}

Para el periodo de noviembre del 2006 a noviembre del 2007 las Figuras 1, 2 y 3 presentan los datos climáticos de temperatura, humedad relativa media y precipitación, respectivamente; correspondientes a la Estación Metereológica de la Estación Experimental Fabio Baudrit Moreno (EEFBM), a 5 km de Carrillos de Alajuela de Costa Rica. 


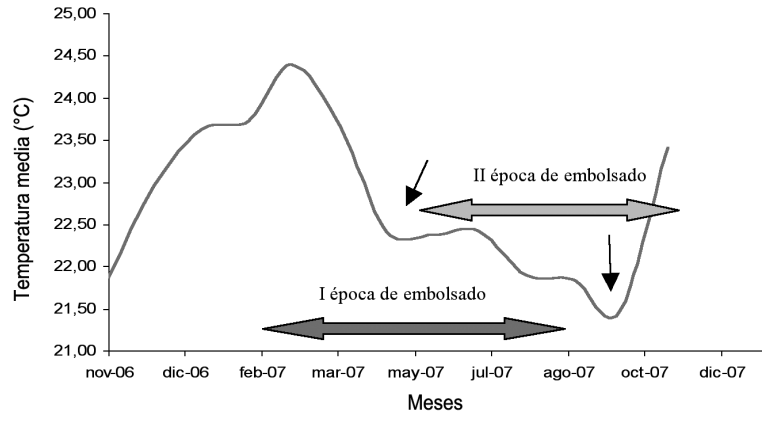

Figura 1. Temperatura media durante la realización del ensayo (noviembre 2006 - noviembre 2007). Datos tomados de la Estación Meteorológica Estación Experimental Fabio Baudrit Moreno. Las flechas señalan el comienzo y el final de la época lluviosa. Carrillos, Alajuela, Costa Rica. 2007.

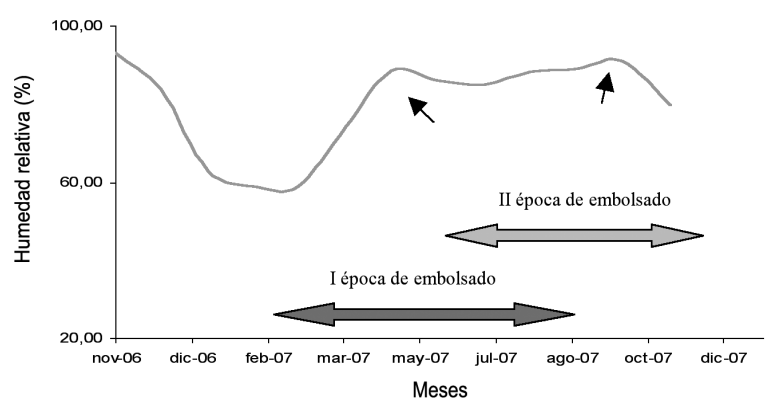

Figura 2. Humedad relativa media durante la realización del ensayo (noviembre 2006-noviembre 2007). Datos tomados de la Estación Meteorológica Estación Experimental Fabio Baudrit Moreno. Las flechas señalan el comienzo y el final de la época lluviosa. Carrillos, Alajuela, Costa Rica. 2007.

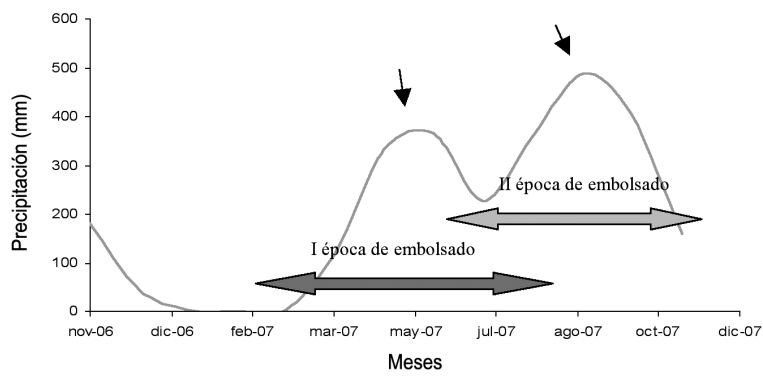

Figura 3. Precipitación total durante la realización del ensayo (noviembre 2006 - noviembre 2007). Datos tomados de la Estación Meteorológica Estación Experimental Fabio Baudrit Moreno. Las flechas señalan el comienzo y el final de la época lluviosa. Carrillos, Alajuela, Costa Rica. 2007.
Durante los meses de mayo a octubre se presentaron una serie de días fríos (Figura 1), húmedos (Figura 2) y lluviosos (Figura 3), lo que coincidió directamente con el desarrollo de los microorganismos.

Las intensas lluvias presentes durante el segundo periodo de evaluación (Figura 3), dañaron las bolsas dejando expuestos rápidamente los frutos, mucho más rápido aún que en el primer periodo. Estas condiciones climatológicas son más propicias para el desarrollo de microorganismos en general, por lo que se descartaron, durante el segundo periodo de evaluación los materiales de papel encerado y de directorio telefónico.

En la Figura 4 se muestran los microorganismos que se aislaron durante ambas épocas de embolsado. Estos microorganismos fueron: a) microorganismo no identificado, b) Colletotrichum spp., c) Pestalotia spp., d) Cylindrocladium spp.y e) Pseudomonas spp.

Se presentó un microorganismo asociado a una lesión redonda que secaba el tejido y mostraba una serie de círculos concéntricos, aparentemente Fusarium spp. (Arauz $2007^{7}$ ), sin embargo, no se logró corroborar con más muestras.

Inicialmente, Pestalotia sp. se presentó asociado a una mancha pequeña grasosa, la cual aumentó en tamaño conforme creció el fruto, hasta convertirse en una gran mancha café que pudría el tejido hasta necrosarlo.

Las bacterias Pseudomonas spp. aparecieron asociadas a las manchas irregulares rojizas con tejido seco (Figura 4).

Se observó un tipo de mancha redonda y rojiza que se denominó "peca" para facilitar las evaluaciones en el campo, esta sintomatología se asociaba al hongo Cylindrocladium spp. Sin embargo, en un estudio realizado en México por Domínguez y Nieto (1996), sobre este tipo de sintomatología (Figura 4), se encontraron en los aislamientos diversos hongos y bacterias no patogénicos, que al ser inoculados de nuevo en frutos sanos no se desarrollaron; dichos autores sugieren que estos tipos de síntomas son causados por deficiencias nutricionales. Es necesario realizar pruebas de patogenicidad para corroborar si esta sintomatología la produce Cylindrocladium spp.

Suhag y Khera (1986), encontraron que al establecer una fertilización reforzada en zinc y nitrógeno, la aparición de microorganismos disminuyó; y que

Arauz, LF. 2007. Identificación de patógenos. Comunicación personal. 


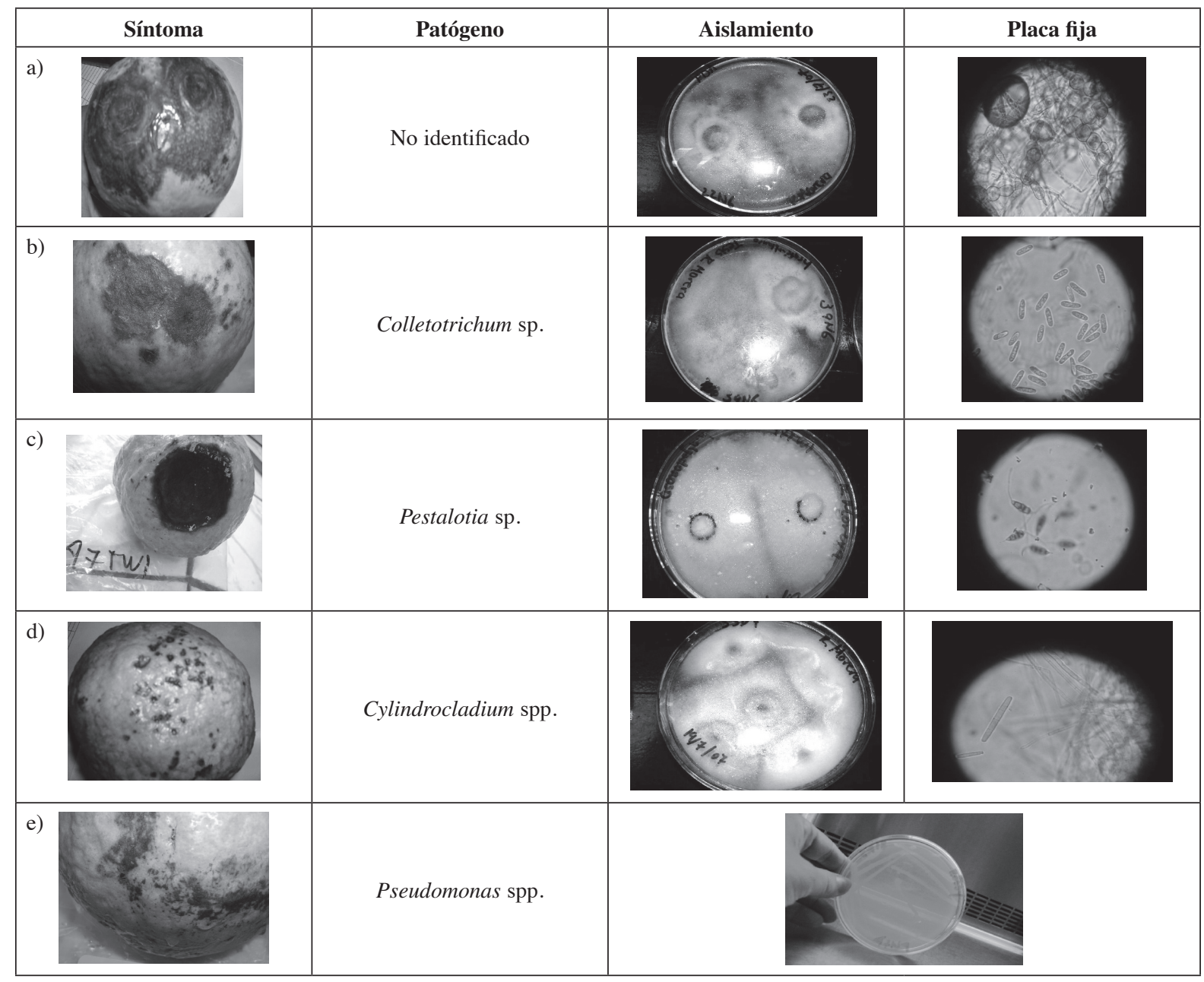

Figura 4. Síntomas, aislamientos y microorganismos asociados al fruto de guayaba para las épocas de embolsado del 21 de febrero al 14 de agosto y del 27 de junio al 20 de noviembre del 2007. Laboratorio de Fitopatología de la Universidad de Costa Rica. San José, Costa Rica. 2007.

el bronceado de las hojas se debió a deficiencias de nitrógeno, fósforo, potasio y zinc. Durante el experimento, se observó el bronceado de las hojas en muchos árboles, a pesar de la fertilización que se le aplicó cada 22 días. Esto sugiere un estudio sobre curvas de absorción de nutrientes para la guayaba, lo cual reduciría considerablemente algunos microorganismos que atacan los frutos y reducen su calidad estética, además, de la posibilidad de ser aceptados en un mercado extranjero.

Se encontró la mayor cantidad de frutos enfermos al utilizar la bolsa de papel encerado, y el mayor número de frutos caídos cuando se utilizó la bolsa de hojas de directorio. Los resultados de la primera época indican que el uso de la bolsa de nylon brindó la mejor protección contra insectos, pero no contra microorganismos asociados a la guayaba. Existió una asociación entre el material de embolsado y la incidencia de microorganismos $\left(\chi^{2}=7,52 \times 10-4\right)$. Durante la primera época de embolsado se presentó una incidencia de microorganismos asociados al fruto en altos porcentajes, en todos los tratamientos; principalmente para antracnosis.

Un estudio realizado en México en una plantación de guayaba (Laksiiminaraya y Moreno-Rivera 1978), se determinó que las enfermedades más importantes 
que atacan a los frutos son: Pestalotia sp. (también encontrado por Pérez et al. 2000), Colletotrichum sp. (Mendes 1995), Dothiorella sp. (Pérez et al. 2000), Cytesporina sp., Mucor sp., Penicillium sp., Botryodiplodia sp. y Phomopsis sp.; además, en Venezuela se han encontrado Cladosporium, Alternaria, Helminthosporium, Curvularia, Fusarium, Beltrania y Tetraploa (Pérez et al. 2000), en Brasil se reportan Puccinia psidii Wint y Erwinia psidii sp. (Mendes 1995). Según Mendes (1995) y Pérez et al. (2000), las enfermedades más importantes de la guayaba corresponden a las dos primeras encontradas en el ensayo; sin embargo, no se ha reportado el ataque de bacterias de género Pseudomonas en frutos.

Como parte de un manejo integrado de las enfermedades, es necesario eliminar ramas y hojas enfermas, y realizar podas para mejorar el paso de la luz, y la ventilación a la plantación; además de mejorar la estructura del árbol, facilitar las prácticas agrícolas y mejorar la calidad del fruto (De Toledo Piza 1994). Sin embargo, aunque en la parcela experimental se realizó una poda óptima, se presentaron altos porcentajes de microorganismos asociados a los frutos, posiblemente por presión de inóculo del resto de la plantación, la cual se observaba claramente afectada por diversos tipos de microorganismos y deficiencias nutricionales, además carecía de una poda adecuada.

La densidad de siembra es un punto muy importante a considerar para manejar enfermedades ya que influye en la ventilación, la competencia por luz, la frecuencia y tipo de poda (De Toledo Piza 1994), además de la producción. En plantaciones convencionales (árbol individual y poca poda) se han manejado distancias de 5 a $6 \mathrm{~m}$ de espaciamiento, para un total de 278 a 400 plantas por hectárea (Iyer y Kurgan 2006). En la plantación comercial donde se efectuó el ensayo, la densidad de siembra era de aproximadamente 1.904 árboles/ha, lo que deja claro que corresponde a una densidad de siembra muy alta, donde es preciso manejar con poda de manera constante el crecimiento y vigor de las plantas. En una investigación realizada por Araujo et al. (1999), se indican distancias mínimas de 5 x 3,5 m; con un total de 571 árboles/ha; si se utilizaran árboles injertados con patrones enanizantes y podas controladas constantes (que aumentan en un $50 \%$ los costos de producción por mano de obra según Manzanero et al. 1996), podría utilizarse la distancia de siembra que se utilizó en la parcela comercial donde se efectuó el ensayo, para generar un mayor rendimiento, mejor control de la sanidad de la plantación, y facilitar la aplicación de fungicidas de manera rotativa y constante, dando como resultado un control de enfermedades y mayor calidad de la fruta.

Las condiciones de la plantación comercial utilizada son similares al resto de la Meseta Central de Costa Rica. Se emplean altas densidades, con poco manejo de poda, lo que se refleja en alta incidencia y severidad de enfermedades en los frutos. Estas pequeñas distancias de siembra generan mayor humedad dentro de la plantación por la poca ventilación, autosombreamiento, reducción de la interceptación de luz adecuada en los árboles, y la generación de un ambiente propicio para el desarrollo de microorganismos y su diseminación.

\section{Primer época de evaluación (transición época seca- época lluviosa)}

En la primera época de evaluación se embolsaron los frutos introduciendo los brotes más jóvenes y las hojas cercanas al pecíolo. Es importante mencionar que en el interior de la bolsa es muy probable que se presentara una alta humedad relativa, producto de la transpiración de las hojas y brotes que acompañaban a la fruta. Este microclima pudo haber favorecido el desarrollo de microorganismos. Además, existen ciertos microorganismos como antracnosis que se encuentran en las hojas, y luego se pasan al fruto (Dodd et al. 1992), el introducir las hojas dentro de la bolsa en conjunto con el fruto aumenta la incidencia de los microorganismos.

Es muy posible que a pesar de las aplicaciones quincenales, las esporas de este hongo sobrevivan en las hojas de árboles poco ventilados, sin poda, mal nutridos, que circundaban la parcela experimental, mientras que los frutos embolsados mantenían cierta humedad relativa en el microclima generado, donde las hojas que se introdujeron al embolsar proporcionaron un ambiente óptimo para el desarrollo de microorganismos.

En la Figura 5 se muestra que durante el primer periodo de embolsado, el tratamiento testigo presentó un alto porcentaje de incidencia de microorganismos asociados al fruto, principalmente por Colletotrichum. También Pestalotia y las bacterias del género Pseudomonas aparecieron en mayores porcentajes que el resto de microorganismos aislados (Figura 5). Dos tratamientos favorecieron al desarrollo de enfermedades como antracnosis, el papel encerado $(48,37 \%)$ y la bolsa con papel de directorio telefónico $(34,14 \%)$. 


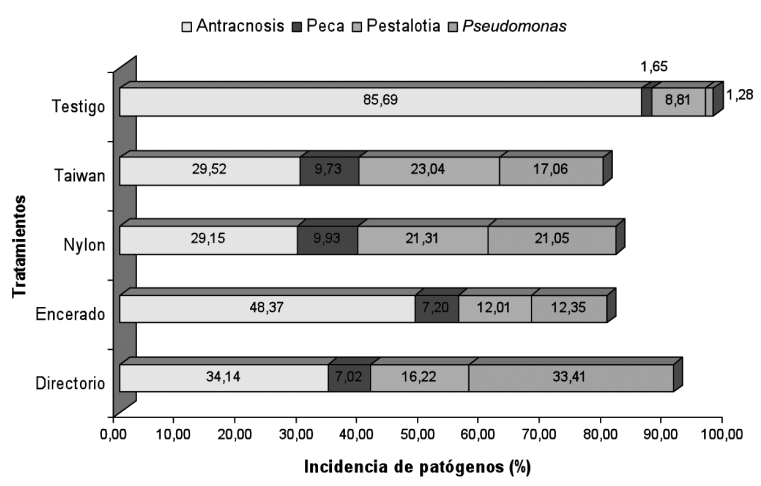

Figura 5. Incidencia de microorganismos asociados al fruto de guayaba durante la primera época de embolsado (febrero-agosto). Carrillos, Alajuela. Costa Rica. 2007.

Cabe resaltar, que no se realizó una aplicación de fungicida previa al embolsado, práctica que podría haber disminuido considerablemente la incidencia de microorganismos. A pesar de que constantemente se realizaban podas en la parcela experimental y se eliminaba cualquier tipo de fuente de inóculo que estuviera presente en el suelo, en la totalidad de la plantación no hubo un manejo adecuado de la poda ni del manejo de desechos vegetales, lo que pudo afectar la aparición de microorganismos en la parcela experimental, y por consiguiente, en los frutos evaluados para todos los tratamientos utilizados.

El largo periodo de llenado del fruto en este tipo de guayaba, deja la posibilidad de aplicar fungicidas sistémicos que puedan degradarse con el tiempo y a su vez proteger el fruto de microorganismos no sólo asociados al fruto, sino a la totalidad de la planta.

\section{Segunda época de evaluación (época lluviosa)}

Durante el segundo periodo de embolsado existieron diferencias significativas $\left(\chi^{2}=0,04773\right)$ en la incidencia de microorganismos asociados al fruto: Colletotrichum sp., Pseudomonas spp., Pestalotia sp. y Cylindrocladim sp. (Figura 6). El tratamiento testigo fue el que presentó el mayor porcentaje de frutos con presencia de microorganismos donde Colletotrichum sp (17,69\%), Pestalotia sp $(11,54 \%)$, Pseudomonas spp $(10,77 \%)$ y Cylindrocladim sp $(8,46 \%)$. Este resultado se dio, posiblemente, porque los frutos del tratamiento testigo no poseían una

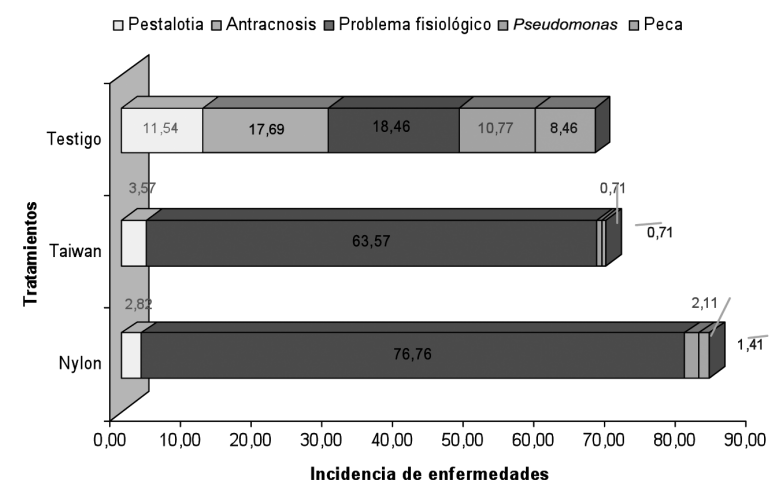

Figura 6. Incidencia de microorganismos asociados al fruto de guayaba durante la segunda época de embolsado (junio-noviembre). Carrillos, Alajuela. Costa Rica. 2007.

barrera física que los protegiera de las esporas de los hongos (Figura 6). Además, para la segunda época se tuvo el cuidado de no introducir hojas ni brotes dentro de los frutos embolsados, por lo que disminuyó la variedad de microorganismos que podían desarrollarse dentro del microclima generado en la bolsa.

En esta segunda época de embolsado, la incidencia de lluvias fue mucho mayor que en la primera (Figura 3), lo que colaboró a la reproducción y diseminación eficiente de hongos como Colletotrichum sp y Pestalotia sp, que se favorecen de ambientes con alta humedad relativa y presencia de agua libre (Pérez et al. 2000, Dodd et al. 1992). La antracnosis se relaciona con alta precipitación y temperaturas moderadas que van de 20 a $27^{\circ} \mathrm{C}$ y una alta humedad (mayor del $80 \%$ ) (Dodd et al. 1992), razón por la cual este microorganismo se representó también durante la época seca, principalmente en frutos embolsados, ya que tenían contacto con las hojas y el microclima era el propicio para su desarrollo.

Durante la época seca, apareció una sintomatología diferente a las presentadas durante el resto del año (Figura 7), la cual consistía de un bronceado marrón en la parte apical del fruto, que iba necrosando el tejido hasta cubrirlo por completo y podrirlo. Se realizaron los respectivos aislamientos en frutos con sintomatologías incipientes, pero no apareció ningún agente causal que pudiera estar asociado a este tipo de sintomatología, por lo que se cree que correspondió a un daño fisiológico. En frutos que presentaban este daño 


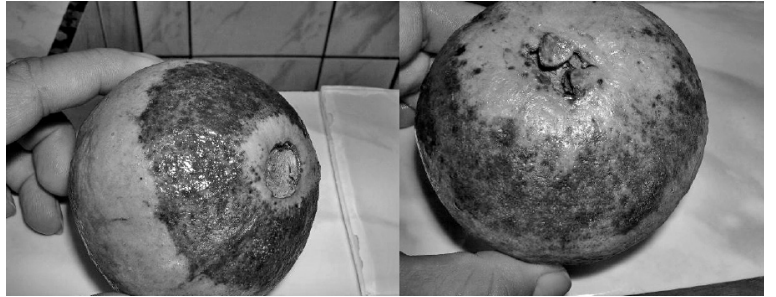

Figura 7. Problema fisiológico presentado en frutos de guayaba de diferentes tratamientos durante la segunda época de embolsado (junio-noviembre). Carrillos, Alajuela, Costa Rica. 2007.

de manera muy avanzada, se encontraron únicamente microorganismos saprófitos.

El aparente daño fisiológico presentó diferencias significativas $\left(\chi^{2}=3,522 \times 10-20\right)$ en su incidencia. El $53,88 \%$ de los frutos perdidos presentaban este tipo de sintomatología. El tratamiento que tuvo la mayor pérdida fue con bolsa de nylon (76,76\%), seguido por Taiwán $(63,57 \%)$ y, por último, el testigo $(18,46 \%)$ (Figura 6). Estos resultados sugieren que durante la época lluviosa no es apropiado utilizar estos materiales para embolsar.

Se cree que este problema fisiológico que pudo deberse a etileno, generado en las raíces de la planta por condiciones de anoxia. El etileno generado por estrés maduraba prematuramente el fruto y lo hacía susceptible a todo tipo de organismos saprófitos.

Las condiciones de anoxia posiblemente fueron facilitadas por las fuertes lluvias que se dieron durante los meses de agosto y octubre del 2007 (Figura 3), de manera que el suelo se saturó (Arauz 20077).

Según Bravo et al. (2005) el hongo Dothiorella sp. es el responsable de causar una sintomatología parecida al síntoma asociado con un problema fisiológico; sin embargo, Jiménez y Santos (1992) informaron síntomas similares a este daño fisiológico, pero aislaron el hongo Macrophomina sp. Ambos hongos citados son saprófitos, son fácilmente confundidos en el momento de identificarlos, mientras que en este ensayo no se encontró ningún microorganismo asociado con esta sintomatología.

Este problema fisiológico no permitió ver claramente los resultados en cuanto a desarrollo de microorganismos asociados al fruto durante la segunda época de embolsado.

El volumen de lluvia anual para la guayaba varía de 1.000 a $2.000 \mathrm{~mm}$ (Schaffer y Andersen 1994), mientras que durante el año de evaluación (ambos periodos de embolsado), se presentaron $2.676,9 \mathrm{~mm}$ de lluvia en la zona de La Garita (a $5 \mathrm{~km}$ del sitio donde se efectuó el ensayo), es probable que esta diferencia de casi $700 \mathrm{~mm}$ de agua, con respecto al rango originalmente tolerado por la guayaba, la cual se puede adaptar a climas áridos, haya provocado desbalances fisiológicos que generaron la pudrición apical del fruto.

\section{AGRADECIMIENTOS}

A la Fundación para el Fomento y Promoción de la Investigación y Transferencia de Tecnología Agropecuaria de Costa Rica (FITTACORI); este proyecto pudo hacerse posible a la empresa Guayatica S.A. representada por Ing. Randall Vargas y su padre, quienes muy amablemente prestaron parte de la plantación para el establecimiento del ensayo. Al Programa Nacional de Moscas de la Fruta, del Ministerio de Agricultura y Ganadería (MAG) y a Sanidad Vegetal por el apoyo financiero y técnico. Un agradecimiento especial al MSc. Carlos Luis Loría y al Dr. Felipe Arauz por sus observaciones en el presente trabajo.

\section{LITERATURA CITADA}

Araujo, F; Urdaneta, T; Salazar, N; Simancas, R. 1999. Efecto de la densidad de siembra sobre el rendimiento en guayabo (Psidium guajava L.) en la Planicie de Maracaibo, Venezuela. Revista de la Facultad de Agronomía (LUZ) 16(1):13-16.

Bravo, V; Rodríguez, D; Sanabria; M; Marín-larreal, M; Santos, R; Pérez, E; Sandoval; L. 2005. Momento de infección por Dothiorella sp. y aparición de síntomas de la pudrición apical del guayabo. Revista de la Facultad de Agronomía (en línea) 22(4):369-381. Consultado 09 enero 2008. Disponible en: www.scielo.org.ve/scielo.php?script=sci_arttext\&pid=S0378$78182005000400005 \& \operatorname{lng}=$ pt\&nrm=iso

Coto, D; Saunders, J. 2004. Insectos plagas de cultivos perennes con énfasis en frutales en América Central. Centro Agronómico Tropical de Investigación y Enseñanza (CATIE) y Universidad Earth. In: Manual Técnico CATIE, no. 52 Guácimo, Costa Rica. 420 p.

De Toledo Piza, C. 1994. A poda da goiabeira de mesa. Boletín Técnico $n^{\circ} 2$. Governo do Estado de Sao Paulo. Secretaria de Agricultura e Abastecimento. 
Coordenadoria de Asistencia Tecnica Integral CATI. Sao Paulo, Brasil. 50 p.

Dodd, J; Estrada, A; Jeger, M. 1992. Epidemiology of Colletotrichum gloesporioides in the Tropics. In: Bailey, J.A.; Jeger, M.J. eds. Pathology and control. Oxon, UK: CAB International. p. 308-325.

Domínguez, J; Nieto, D. 1996. Firmeza y disminución de peca en frutos de guayaba (Psidium guajava L.) en Jalpa, Zacatecas. Revista Chapingo Serie Horticultura 2(2):223-226.

Jiménez, A; Santos, R. 1992. Estudios biológicos y morfológicos del hongo causante de la pudrición apical de los frutos del guayabo (Psidium guajava L.). Revista de la Facultad de Agronomía (LUZ) 9:77-96.

Instituto Meteorológico de Costa Rica. 2006. Recopilación de datos de registros climatológicos de las Estaciones Experimentales Fabio Baudrit Moreno y Argentina de Grecia. Costa Rica. 22 p.

Iyer, C; Kurian, R. 2006. High density planting in tropical fruits. Principles and practices. International Book Distributing. Bangalore, India. 260 p.

Laksiiminaraya, S; Moreno-Rivera, M. 1978. Enfermedades y desórdenes en la producción y mercadeo de la guayaba mexicana. Chapingo (Nueva Época: enerofebrero) (9):27-33.

Manzanero, R; Morillo, F; Rincón, E; Urdeta, F; Graterol, J. 1996. Seguimiento productivo y económico de unidades de producción de guayaba (Psidium guajava
L.) en el municipio Mara del Estado de Zulia. Revista de la Facultad de Agronomía (LUZ) 13:469-484.

Mendes, F. 1995. Cultura da goiabeira. Jaboticabal: FUNEP. Estado de Sao Paulo. Brasil. 48 p.

Pérez, E; Santos, R; Montiel, A; Marín, M; Sandoval, L. 2000. Micoflora de una plantación de guayabo (Psidium guajava L.) en la planicie de Maracaibo del estado de Zulia. Revista de la Facultad de Agronomía (LUZ) 17:373-383.

Román, R; Juang, T. 1999. Cultivo de la guayaba. IDA. MAG. Misión Técnica de la República de Taiwán en Costa Rica. San José, CR. 21 p.

Schaffer, B; Andersen, P. 1994. Handbook of environmental physiology of fruit crops. Vol III. Subtropical and Tropical Crops. USA. CRC Press. Boca-Ratón, Florida. 310 p.

SEPSA (Secretaría Ejecutiva de Planificación Sectorial Agropecuaria). 1998. Sector Agropecuaria. (Boletín Estadístico). San José, Costa Rica. 28 p.

Suhag, L; Khera, A. 1986. Studies on the variation in nutritional level of wilted, regenerated and healthy trees of guava cultivar Bañarais Surha. Indian Phytopathology 39(1):90-92.

Tosi, J. 1969. Mapa ecológico, República de Costa Rica: según la clasificación de zonas de vida del mundo de L.R Holdridge. San José, Costa Rica. Instituto Geográfico Nacional. Escala 1: 750000. Color para clave de zonas de vida. Serie 173599. 
